\title{
STUDENT PERFORMANCE IN A TECHNOLOGY-ENHANCED AVIATION METEOROLOGY COURSE
}

\author{
Michael R. Witiw and Kathleen Kelly-Benjamin
}

Florida Institute of Technology

\begin{abstract}
In recent years, as the presence of technology in the classroom increased, methods for using technology also increased, but at a much slower pace. With this in mind, this study looked to current educational theory for an effective way of employing computer technology in the aviation meteorology classroom. One method that showed promise consisted of coupling technology with advance organizers. Advance organizers are pertinent introductory materials presented to students prior to formal instruction. Their purpose is to provide cognitive anchorage for the ideas that follow in subsequent instruction. In the past, advance organizers have met with mixed success, however, recent research shows that when properly constructed, they can be very effective in increasing students' academic performance. In this study, the effectiveness of computer technology as a means to present advance organizers was studies. The sample consisted of 67 students who received the advance organizers either by technology via computer monitors or by paper hard copy. Students were statistically matched and data were analyzed using multiple analysis of covariance (MANCOVA) and follow-on univariate analyses of covariance (ANCOVA). In this study, statistically significant results showed computer technology to be effective in increasing performance among aviation meteorology students.
\end{abstract}

\section{Introduction}

As the use of technology has increased in many areas of education, the methods for using it have also increased, albeit at a much slower pace. Initially, computer technology was used as an efficient method of practice and repetition (Clark, 1985). Today, new methods include simulation and data sharing (Newman, 1990; Semrau \& Boyer, 1994). Semrau and Boyer (1994) recommend using technology to examine data, interpret them, and look for trends in the data. On the whole, however, few new ideas for integrating technology into the college classroom have been implemented and a great need remains for new models to provide guidance for the effective implementation of technology (Senechal, 1991).

In an attempt to find an effective method of integrating computer technology in the meteorology classroom, applied recent advances in educational theory in a controlled, quasiexperimental study. In this study, the impact routine use of available technology can have on students' understanding of basic aviation meteorology was studies. The method explored was the use of technology to present advance organizers. An advance organizer consists of introductory material presented to students prior to formal instruction (Ausubel, 1960). These advance organizers then provide the cognitive anchorage for the more detailed concepts that follow.

Prior to the current research, a pilot study was conducted. That study provided evidence that computer technology, when used in the aviation meteorology classroom, had a positive effect on student outcomes (Witiw \& Horton, 1996). The pilot study, however, did have limitations. No treatment was given to the control group and the experimental group was quite 
small $(\underline{n}=5)$. Because the results of the pilot study were encouraging, the research proceeded with a larger, more comprehensive study where the following research questions were developed: Do advance organizers presented through computer technology enhance students' factual knowledge, conceptual knowledge or problem solving ability? If an increase in knowledge is initially observed, does it persist with time?

\section{$\underline{\text { Technology and Advance Organizers }}$}

Meng and Patty (1991) compared two types of advance organizers by employing computer-assisted instruction techniques. Their experimental study tested achievement on immediate and delayed post-tests with subjects grouped by learning styles, Mayer tested advance organizers (1979) and conceptual models (1989) and found varying degrees of success depending upon whether knowledge was factual, conceptual or problem-solving. Building on this previous work, this research investigated two types of advance organizers that were identical in content but were different in the type of media used to present them. Experimental groups had access to displays on video monitors provided through computer technology, while the control group received printed charts similar to those available for many years in the meteorology classroom.

\section{Significance of the Problem}

Though computer-assisted instruction has been used for many years, only recently has its use gone beyond drill and practice (Clark 1985,1991). Because no experimental research has addressed the appropriateness of different methods of using technology in the meteorology classroom, one goal of this study was to implement, test, and validate one method for doing so. It was hoped this would result in a definitive strategy for using technology to enhance students' understanding of basic aviation meteorology.

Ever since Ausubel (1960) introduced the idea of advance organizers, controversy has existed as to their utility and their most effective use. Development in the use of advance organizers matured with the work of Mayer (1989) and Meng and Patty (1991). Coincidentally, innovative ideas for the use of technology were put forth by Ellis (1992) with his suggestion of using technology as a dynamic means to present advance organizers.

The advance organizers developed for the current study were modeled after Mayer's $(1979,1989)$. He explored illustrative advance organizers and the types of knowledge they enhance. He saw usefulness in illustrative advance organizers especially when presenting technical concepts and particularly when the knowledge concerned was other than factual. Mayer's work followed a period when much work was being done with advance organizers, but with widely varying results (Barnes \& Clawson, 1975). Mayer (1989) found the advance organizers he used effective in improving a student's conceptual knowledge and problemsolving ability. He reached success when he adapted one type of advanced organizer to a specific situation. Mayer insisted that organizers, or conceptual models (a term he later adopted) must be complete, concise, correct, and conceptual.

This research also had a strong basis in Meng and Patty's (1991) work. Meng and Patty not only compared the effectiveness of different types of advance organizers, but also incorporated cognitive styles and longevity of effects into their study. They compared two types of advance organizers and tested their short and long-term effectiveness. Their approach added experimental rigor by ensuring all participants received a treatment. Similar to Meng and Patty, two types of advance organizers were compared. Also investigated was their work of 
looking at the effects of organizers after a fixed amount of elapsed time. The study built upon past research related to advance organizers (Ausubel, 1960; Corkill, Bruning, \& Glover, 1988; Mayer 1979, 1989; and Meng \& Patty 1991).

Over the years, other researchers have broadened Ausubel's original definition of an advance organizer by defining and testing different types of organizers. Several studies have shown that properly constructed advance organizers can be either abstract or concrete; verbal or illustrative (Corkill et al., 1988; Kloster \& Winne, 1989; Meng \& Patty, 1991). With this in mind, the type of organizers used in the current study approximated many of the newly defined types. The information presented to current research subjects consisted of illustrative (not written) advance organizers that were delivered via technology (Meng \& Patty, 1991). Because the information relied upon specific events, these events fit Corkill et al.'s description of concrete organizers or what Ellis (1992) termed micro-events. They also closely parallel what Mayer (1989) termed models in that they were concrete, concise, and demonstrated the relationship between different elements of a system. Finally, an instructional technique described by Cobb (1994) as theoretical pragmatism was utilized. This paradigm draws on the work of Ausubel, Piaget, constructivism, and Vygotsky's social cognitive development. By using an advance organizer as a focus, students were permitted to explore their own concepts prior to instruction.

Specifically, the advance organizers or micro-events (the term these researchers used when referring to technology-displayed data) consisted of geographical maps with weather data superimposed, vertical atmospheric data profiles, and surface weather observations. For example, a micro-event on fronts displayed a surface chart, several upper level atmosphere charts, radar displays, satellite imagery, and current surface weather observations for several reporting stations.

This research predicted that combining technology with advance organizers would promote increased overall course success as well as higher levels of success in the conceptual and problem-solving aspects of aviation meteorology.

\section{Methods}

\section{Subjects}

This experiment took place at Florida Institute of Technology where aviation meteorology is a required course for all students entering the aviation program. The course usually is completed during the first semester of freshman year. The accessible population ( $\underline{n}=$ 67 ) included all students enrolled in this course during a single semester. This university's aviation program draws students from across the United States as well as internationally.

Three intact sections, as assigned by the university registrar, ranged from 21 to 24 students each. These sections comprised the control group $(\underline{n}=24)$ experimental group $1(\underline{n}=22)$ and experimental group $2(\underline{n}=21)$.

\section{Instruments}

Five paper and pencil tests were used in this study and consisted of multiple choice and free-response items. Standardized rubrics were used to assess the open-ended answers. Questions were designed with help from the test bank included in the Instructor's Manual to Accompany Essentials of Meteorology (Ahrens, 1993). A pretest was administered prior to 
instruction. Its results were used as a covariate in the statistical analysis. Test one covered the first three weeks of instruction. Its primary use was to determine an appropriate test length and the suitable number of multiple choice and open ended questions. Test one results were not incorporated into the statistical analysis. Tests two, three, and four each contained 33 scored items, and each was administered during a 50-minute classroom period. Twenty-one of the items on each test were multiple choice questions, or required a specific short answer. The remaining 12 items derived from six opened-ended questions, each of which contained two dichotomously scored items.

The second, third and fourth tests covered the material presented in each of three, three-week periods. Treatments took place during the last two of these periods, with tests administered following each three week period. All three sections were tested on the same days. The comprehensive final examination was administered following course completion in accordance with the university-published final examination schedule. This occurred seven weeks after completion of the first treatment period, and four weeks after completion of the second treatment period. The final examination included 75 scored items, derived from 47 multiple choice or very short answer questions and 14 open ended questions, each of which contained two scored items. About 50 percent of these questions had appeared previously on tests one through four. The final exam was administered in a two hour period.

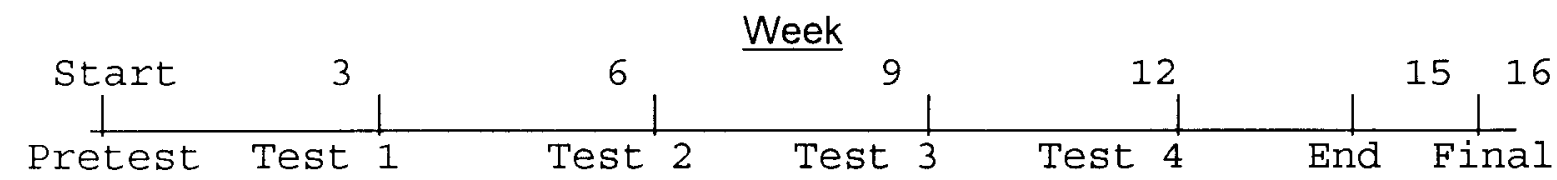

Figure 1. Timeline of testing schedule. Semester ended after Week 15. Final examination took place during Week 16.

The delayed post-test, which was incorporated into the final was designed with the work of Meng and Patty (1991) in mind. They found differences in achievement between measurements made immediately after treatment and those that were delayed. The intent was to test the persistence of treatment effects.

\section{Design}

This research used a quasi-experimental approach with a control group $(\underline{n}=24)$ and two experimental groups $(\underline{n}=22,21)$. A pretest, two immediate post-tests and a delayed

Table 1

Treatment Schedule

\begin{tabular}{|l|l|l|l|c|}
\hline Group & Weeks 1-6 & Weeks 7-9 & Weeks 10-12 & Weeks 13-15 \\
\hline Experiment 1 & Identical & Treatment & Treatment & Identical \\
\hline Experiment 2 & Identical & Control & Treatment & Identical \\
\hline Control & Identical & Control & Control & Identical \\
\hline
\end{tabular}


post-test. A post-test followed each of two treatment periods were administered. The delayed, comprehensive post-test followed the termination of all treatment. The first experimental group $(\underline{n}=22)$ received micro-events during both treatment periods. The second experimental group $(\underline{n}=21)$ only received treatment during the second treatment period (Table 1$)$. Analysis of covariance provided the control for pre-existing differences among groups.

\section{Procedures}

The course curriculum, syllabus, and assignments were identical for all three groups. The lecture format used during the first six weeks of the course was identical for all groups. The second six weeks consisted of the treatment periods. Content for all lectures and labs were identical during this time. For the lab periods, however, the media used varied.

The students completed five tests. Scores from tests three and four and the final exam were used to compare success among the three groups. Tests one and two were administered prior to the treatment periods. Test one provided the necessary information to gauge the appropriate number of questions for subsequent tests, and it sensitized students to the type of questions to expect. Test two scores provided a covariate.

The experimental treatment consisted of micro-events introduced via technology by the instructor during a laboratory period. Labs preceded the formal presentation of related material introduced during the lecture portion of the course. Examples of micro-events included frontal systems and air masses, severe weather and tropical weather. Control groups received hardcopy versions of the micro-events (advance organizers). These consisted of charts and alpha numeric data rather than the computer based versions. The control group received information identical to that contained in the micro-events. Micro-events and advance organizers were based upon current meteorological conditions. The content for a particular session addressed material that was presented by lecture during the next two to three classroom periods. For example, various charts showed how the cold front looks at the surface, and how it looks aloft, as well as its relation to the jet stream and individual surface observations and forecasts. A subsequent lecture, using several meteorological charts, addressed the actual physics of a cold front. Each chart included data from a different level of the atmosphere. These levels extended from the surface of the earth to high in the atmosphere. All sections had an equal amount of laboratory time--25 minutes per session.

Each week, each section viewed a micro-event (advance organizer for the control), such as the situation surrounding a frontal system or a severe weather event. The data were actual real-world and recent. Discussion commenced when the students completed viewing all components, . The discussions were based upon instructor-led questions. At the end of the lab period, the instructor asked the class for any conclusions based on the exercise.

\section{Data Analysis}

A quasi-experimental approach with one control group and two experimental groups and a pretest provided the data for analysis. Multiple regression correlation helped to determine predictor variables and to statistically match the groups. Covariates entered as a set included math and verbal SAT scores, high school GPAs, pretest scores, and the scores of a test administered prior to the commencement of the experiment. Significance testing of the semipartial correlation coefficient was used to test the significance of the group membership for each of the experimental groups. A multiple analysis of covariance (MANCOVA) allowed adjustment of post-test scores for differences in the covariates. It also helped control Type I 
error rates for the six outcomes being tested. The analysis included follow-up ANCOVAs for significant main effects.

To ensure statistical rigor, an initial significance level of .05 was used as well as a power of .80. Effect size was calculated using effect size index. To meet the significance level and power requirements for $\underline{n}=67$, the minimum required effect size index for addition of the two group membership variables was .151 .

\section{Results}

Of the many multivariate statistical techniques available, multiple analysis of covariance (MANCOVA) is the preferred method when covariates are present and the significance of group membership is being tested (Tabachnik \& Fidell, 1989). MANCOVA, therefore, served as an omnibus test to evaluate the relationship between treatment group membership and the dependent variables. Where this relationship showed initial significance, additional follow-on univariate analysis of covariance (ANCOVA) computations were done.

\section{Significance of Covariates}

As a set, the covariates were significant for all dependent variables at the .05 significance level (Table 2). Additionally, the minimum effect size index, $\underline{f}^{2}$ was calculated to be .82 , and power exceeded .99 in the model for all dependent variables.

Table 2 shows that, as a set, the covariates contributed a significant amount of the variance for each of the dependent variables tested. The model, therefore made adjustments for the initial differences between subjects. Furthermore, as seen in Table 2, when group membership was entered as a set, the set contributed a significant portion of the variance for four of the six dependent variables being studied.

\section{Follow-on ANCOVAs}

Follow-on ANCOVAs, in a protected F-test, were made for the four dependent variables (IPT, CPT, CON, and PROB) the MANCOVA analysis indicated were significant. For these four dependent variables, group membership was a significant factor in the omnibus test. As described by Haase and Ellis (1987), significance levels in these follow-on tests were adjusted for the number of tests being accomplished. As a result of the four follow-on tests, the new alpha level calculation equaled $.0125(.05 / 4)$. Table 3 presents the four follow-on, univariate ANCOVAs for group membership. The critical $\underline{F}$ value for these calculations ( $d f=2,59$ ) was determined to be 4.87 .

As seen from Table 3, results of the initial post-test and conceptual knowledge were significant at an alpha level of .0125 . 
Table 2

Hierarchical Cumulative $\mathrm{R}^{2}$ Analysis for the addition of group membership in the MANCOVA Model

\begin{tabular}{|c|c|c|c|c|}
\hline IV Set Added & $d f$ & cum. $R^{2}$ & 1 & $\mathrm{~F}$ \\
\hline \multicolumn{5}{|c|}{ Initial Post-test } \\
\hline Set A (covariates) & 5,61 & .450 & & $9.99^{* *}$ \\
\hline Set B (group membership) & 2,59 & .553 & .103 & $7.03^{*}$ \\
\hline \multicolumn{5}{|c|}{ Delayed Post-test (DPT) } \\
\hline Set $A$ (covariates) & 5,61 & .546 & & $14.68^{* *}$ \\
\hline Set B (group membership) & 2,59 & .579 & .033 & 2.39 \\
\hline \multicolumn{5}{|c|}{ Comprehensive Post-test (CPT) } \\
\hline Set A (covariates) & 5,61 & & .543 & $14.48^{* *}$ \\
\hline Set B (group membership) & 2,59 & .606 & .063 & $4.87^{*}$ \\
\hline \multicolumn{5}{|c|}{ Factual Knowledge (FAC) } \\
\hline Set A (covariates) & 5,61 & .464 & & $10.57^{* *}$ \\
\hline Set B (group membership) & 2,59 & .505 & .041 & 2.52 \\
\hline \multicolumn{5}{|c|}{ Conceptual Knowledge (CON) } \\
\hline Set A (covariates) & 5,61 & .545 & & $14.36^{* *}$ \\
\hline Set B (group membership) & 2,59 & .620 & .075 & $6.02^{*}$ \\
\hline \multicolumn{5}{|c|}{ Problem Solving (PROB) } \\
\hline Set A (covariates) & 5,61 & .563 & & $15.72^{* *}$ \\
\hline Set B (group membership) & 2,59 & .607 & .044 & $3.41^{*}$ \\
\hline
\end{tabular}

Note $\underline{n}=67$

$\mathrm{p}<.05 ;{ }^{*} \mathrm{p}=.0001$ 
Table 3

Follow-on Univariate ANCOVAs of the Comprehensive Post-test, Initial Post-test, Conceptual Knowledge, and Problem-Solving Ability

\begin{tabular}{|l|l|l|}
\hline Dependent Variable & df & Univariate F \\
\hline CPT & 2,59 & 4.72 \\
\hline IPT & 2,59 & $6.79^{*}$ \\
\hline CON & 2,59 & $5.82^{*}$ \\
\hline PROB & 2,59 & 3.30 \\
\hline
\end{tabular}

Note: $\underline{n}=67^{\circ} \underline{p}<.0125$

Table 4 shows the effect size indices and power calculated for the addition of group membership for the two dependent variables showing significance.

Table 4

Effect Size Indices for Group Membership of Initial Post-test, and Conceptual Knowledge

\begin{tabular}{|l|c|c|c|c|}
\hline Dependent Variable & $\mathrm{df}$ & $\mathrm{f}^{2}$ & $\mathrm{~L}$ & Power \\
\hline IPT & 2,59 & .261 & 15.4 & .95 \\
\hline CON & 2,59 & 197 & 11.6 & .87 \\
\hline
\end{tabular}

Note: $\underline{n}=67$

Therefore, the results of this study indicated that computer technology, when used to present concepts prior to formal classroom instruction, had a significant, positive effect on the students' conceptual scores as well as on scores on post-tests administered immediately after periods of instruction.

\section{Discussion and Conclusions}

\section{Discussion of Results}

In this study, research questions were developed that were based upon the work of these previous investigators. Following Mayer $(1979,1989)$, the relationship of the use of technology and a student's factual, conceptual, and problem-solving knowledge was explored. Meng and Patty (1991) provided the basis for the study of the relationship between using technology and students' success on immediate, delayed, and comprehensive post-tests.

Factual knowledge, conceptual knowledge, and problem solving ability. The effect of presenting micro-events via computer technology on the three types of knowledge as part of the omnibus MANCOVA, and follow-up univariate ANCOVAs was explored. Of factual and conceptual knowledge as well as problem-solving ability, statistically significant positive results 
were only found concerning conceptual knowledge. These were in a positive direction in favor of technology.

Immediate post-tests, comprehensive post-tests, and delayed post-tests. As part of the omnibus MANCOVA, the longevity of the effect of treatment was tested. Scores were assigned to appropriate combinations of post-tests. To test any immediate or short term effect, one score was assigned to the sum of the scores of the two tests administered immediately after the treatment periods (IPT). Another score was assigned to the number of correct answers a student obtained on the part of the final examination that was applicable to the treatment period (DPT). Finally, a separate score was assigned to represent the sum of the IPT and DPT scores (CPT). Statistically significant results were found only for the immediate post-tests. Again, these results were in a positive direction in favor of the use of technology.

\section{Conclusions}

For the students involved in this study, the use of technology to present illustrative advance organizers proved effective in increasing their conceptual knowledge of basic aviation meteorology. Additionally, this use of technology also proved effective in significantly increasing students' knowledge of basic aviation meteorology when this knowledge was tested immediately after treatment periods.

Statistical testing of any effect the technology may have had on the students' factual knowledge or problem-solving ability was inconclusive. Likewise, any long-term effect of the treatment was not shown to be statistically significant in this study.

Future studies are needed that more completely incorporate the cognitive style or aptitude of the learner. This project would help determine the type of student for which technology is most effective. A large sample consisting of a broad spectrum of past performance and aptitudes would be required.

This study was inconclusive concerning the effect of technology on factual knowledge and problem solving ability. To more thoroughly investigate these areas an experimental study should be conducted over a longer period of time than a six week period. Long term persistence of any treatment effects should be studied. This study indicated the strongest effects to be in the near term. Although the delayed effect for the treatment remained positive, the lack of statistical significance prevented any firm conclusions. A longer term, larger study might determine the relationship of performance and elapsed time since completion of treatment.

\section{References}

Ahrens, C. D. (1993). Instructor's Manual to Accompany Essentials of Meteorology, St. Paul, MN: West.

Ausubel, D. P. (1960). The use of advance organizers in the learning and retention of meaningful material. The Journal of Educational Psychology, 51, 267-272.

Barnes, B. R. \& Clawson, E. U. (1975). Do advance organizers facilitate learning?

Recommendations for further research based on the analysis of 32 studies. Review of Educational Research, 45, 637-659.

Clark, R. E. (1985). Evidence for confounding in computer-based instruction studies: Analyzing the meta-analyses. Educational and Computing Technology Journal, 33, 249-262. 
Clark, R. E. (1991, February). When researchers swim upstream: reflections on an unpopular argument about learning from media. Educational Technology, 34 - 40.

Cobb, P. (1994). Where is the mind? Constructivist and sociocultural perspectives on mathematical development. Educational Researcher, 23, 13-20.

Corkill, A. J., Bruning, R. H., \& Glover, J. A. (1988). Advance organizers: Concrete versus abstract. Journal of Educational Research, 82, 76-81.

Ellis, M. E. (1992). Applying cognitive theories to multimedia instructional design. (ERIC Document Reproduction Service No. 354561).

Haase, R. F. \& Ellis, M. V. (1987). Multivariate analysis of variance. Journal of Counseling Psychology, 34, 404-413.

Kloster, A. M., \& Winnie, P. H. (1989). The effects of different types of organizers on students learning from text. Journal of Educational Psychology, 81, 9-15.

Mayer, R. E. (1979). Can advance organizers influence meaningful learning? Review of Educational Research, 49, 371-383. 43-64.

Mayer, R. E. (1989). Mode/s for understanding. Review of Educational Research, 59(1),

Meng, K. \& Patty, D. (1991). Field dependence and contextual organizers. Journal of Educational Research, 84, 183-189.

Newman, D. (1990). Opportunities for research on the organizational impact of school computers. Educational Researcher, 19, 8-13.

Semrau, P. \& Boyer, B. A. (1994). Enhancing learning with interactive video. Changing college classrooms, 213-229, Jossey-Bass Publishers: San Francisco.

Senechal, L. (1991). Perspectives for computing in mathematics technology in higher education: Current reflections. Fifth in a series. (ERIC Document Reproduction service No.364431).

Tabachnik, B. G. \& Fidell. L. S. (1989). Using multivariate statistics. (2 ${ }^{\text {nd }}$ ed.), New York: Harper Collins.

Witiw, M. R. \& Horton, P. (1996). Technology in the aviation meteorology classroom: A pilot study. Collegiate Aviation Review, 18-26. 